\title{
Nuevas aplicaciones de equipos centrífugos en minería
}

Henry Brañes', Cesar Osorio ${ }^{2}$

\section{Resumen}

Esta investigación se centra en el análisis de nuevas aplicaciones de equipos centrífugos en minería, basándose en las múltiples fallas geotécnicas de componentes mineros que se han visto en los últimos años, las cuales están provocando contaminación del medio ambiente y descarga de efluentes mineros no adecuados para su disposición en los ríos. Por estas razones, la sociedad y las comunidades exigen mayor regulación y control de la industria minera. Sin embargo, esta investigación propone caracterizar dichas tecnologías y escoger la más eficiente y de menos costo para su puesta en marcha. Así mismo, las operaciones mineras se han enfocado en incrementar su producción, pero han descuidado el adecuado control de construcción y operación de componentes mineros, como el ambiental, el social, entre otros. El artículo evalúa los separadores no solo porque remueven sólidos, sino porque también concentran los sólidos separados y los transfieren (con poca o ninguna pérdida de líquido) hasta el dispositivo que se haya elegido para el manejo de los sólidos separados, reduciendo la pérdida de líquido y reduciendo el manejo de los sólidos deshechos y sus costos.

Palabras clave: equipo centrífugo, geotecnia, minería, tratamiento de efluentes. 


\section{Introducción}

La contaminación de ríos es uno de los problemas ambientales más importantes en la industria minera.

Sin embargo, el agua se contamina por culpa de la actividad humana, debido al aumento de la población cada año, requiriendo mayor cantidad de agua, comida, transporte, vestimenta, recursos y espacio para vivir. A causa de lo anterior, se produce la emisión de gases tóxicos, la contaminación por desechos, metales y pesticidas; la descarga de desechos químicos y material radiactivos; o incluso accidentes, como los derrames de petróleo. (Ivoflores. blogspot.com, 2010)

Por lo cual, uno de los principales factores de contaminación tanto de ecosistemas como de fuentes de aguas es la descarga directa sin tratamiento previo de las aguas residuales en los cuerpos receptores (ríos, lagos, quebradas secas o el mar), lo que amenaza la sostenibilidad del recurso y pone en riesgo la salud de la población. (SUNASS, 2015)

En la actualidad, las plantas de tratamientos de efluentes tienen un alto costo de inversión, generando un déficit en la implementación de estos equipos. Los equipos centrífugos en la minería son utilizados para el tratamiento de afluentes con el fin de reducir los impactos generados al medio ambiente y la sociedad. Este tipo de equipos pueden ser utilizados en la pequeña, mediana y gran minería, puesto que se requiere de poca inversión para obtenerlos.

"La contaminación de los ríos es la problemática más antigua, fundamentalmente generada por las diversas actividades humanas; puesto que la población va requiriendo más agua dependiendo la necesidad" (SUNASS, 2015).

Entre las causas de su contaminación más notables son:

- Basurales

- Contaminación con metales pesados en desechos mineros

- Pesticidas en agricultura

- Desechos de materia orgánica

- Excrementos

- Excesos de alimento

- Contaminación en plantas de celulosa con metales pesados

- Contaminación por fosfatos como detergentes. (SUNASS, 2015)

El artículo analiza la aplicación de 
los equipos centrífugos en la industria minera, en especial para la utilización en el tratamiento de efluentes mineros con la finalidad de obtener disminuir los contaminantes y obtener un cumplimiento a las regulaciones ambientes.

\section{Fundamento teórico}

\section{Drenaje ácido de botaderos y mina}

Las aguas ácidas son generadas a causa de un fenómeno denominado "drenaje ácido", el cual es originado cuando minerales que contienen sulfuros metálicos, entran en contacto con el oxígeno, agua y bacterias, como la thiobacillus ferrooxidans. Estas se generan por intervención humana a través de los botaderos y depósitos de relaves en fase de cierre, cuando el drenaje escurre hacia aguas superficiales o desciende al nivel freático. (Rimarachin y Moreno, 2015)

\section{Procesos metalúrgicos e hidro-me- talúrgicos}

Tratamiento de efluentes mineros. El agua es crítica para todos los tipos de minería. En algunos lugares las precipitaciones significativas pueden llevar a una escorrentía ácida desde el drenaje de la mina, pilas de desechos y minas de superficie, contaminando arroyos y ríos. En lugares más secos, la minería y el proceso de minerales utilizan grandes volúmenes de suministros de agua escasos y también pueden contaminar el agua subterránea con químicos tóxicos.

\section{Sedimentación y centrifugación}

La sedimentación: "se trata de una operación de separación sólido-fluido en la que las partículas sólidas de una suspensión, más densas que el fluido, se separan de éste por la acción de la gravedad" (Coy y González, 2016).

La centrifugación:

este es uno de los métodos de separación de mezclas que puede usarse cuando la sedimentación es muy lenta; con el fin de acelerar esta operación la mezcla se coloca en un recipiente que se hace girar a gran velocidad; debido a la acción de la fuerza centrífuga los componentes más pesados se sedimentan más rápidamente y los livianos quedan como sobrenadante. (Coy y González, 2016)

Revista Agunkuyâa. Volumen 2: 48-55. 2018 | 51 


\section{Eficiencia del tratamiento de aguas}

Tradicional y centrifugación depende del diseño

\section{Reclamos sociales}

La lucha social en contra de la minería, especialmente la metálica, ha venido creciendo a medida que generaciones enteras han visualizado los impactos ambientales y sociales, mismas amenazas que se han intensificado y extendido con el ingreso de nuevos proyectos en una era que se ha denominado recolonización. (Confraternizarho y.blogspot.com, 2012)

\section{Efluentes mineros}

"El origen de los efluentes líquidos mineros podemos encontrarlo en los distintos procesos que se llevan a cabo en la mina, así como en el drenaje de lluvias que caen sobre el lugar" (Horizonteminero.com, 2016).

\section{Sólidos en suspensión}

"Los sólidos en suspensión son partículas que permanecen en suspensión en el agua debido al movimiento del líquido o debido a que la densidad de la partícula es menor o igual que la del agua" (Chambi, 2018). La sedimentación es la vía más adecuada para separar los sólidos.

\section{Metales disueltos}

Los sólidos disueltos son la suma de los minerales, sales, metales, cationes o aniones disueltos en el agua. Esto incluye cualquier elemento presente en el agua que no sea (H20) molécula de agua pura. El cambio de $\mathrm{pH}$ modifica el estado de disuelto ha suspendido, también se consigue removerlos con el empleo de polímeros. (Cadena y Cuervo, 2018)

\section{Planta de tratamiento de aguas residuales en minería}

El tratamiento de las aguas residuales, consiste en poner en marcha procesos físicos, químicos o biológicos para poder eliminar los contaminantes de las aguas residuales, con el fin de producir efluentes no dañinos, que se puedan reutilizar.

En la actualidad hay una serie de métodos, procesos, tecnologías, para el tratamiento de aguas residuales, los cuales con el pasar del tiempo van actualizándose, modernizándose 
y haciéndose cada vez más eficientes y eficaces. (Johnson y Hallberg, 2005).

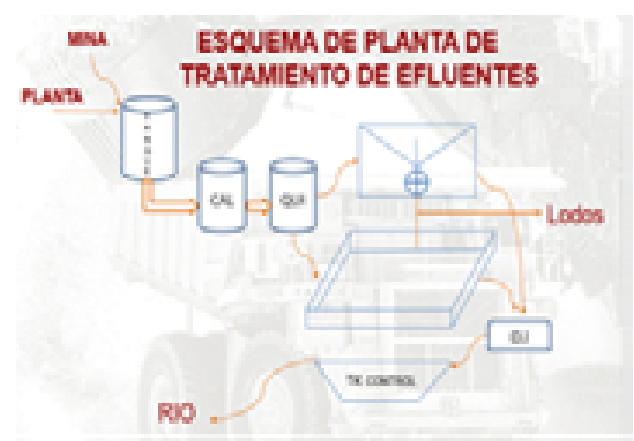

Figura 1. Esquema: planta de tratamiento actual Fuente: elaboración propia

\section{Hallazgos}

Efectividad del proceso. Depende de la velocidad que alcanza la partícula dentro de la centrífuga, en comparación con lo que ocurriría bajo influencia de la gravedad. La relación de velocidades de la partícula en la centrífuga respecto de aquella observada con gravedad se conoce como efecto centrífugo o número g:

$$
\mathrm{Z}=\mathrm{w} 2 \mathrm{r} / \mathrm{g}
$$

La fuerza desarrollada en una centrífuga es $\mathrm{Z}$ veces la de la fuerza de gravedad.

\section{Equipos}

\section{Filtro centrífugo}

- Pretratamiento de efluentes/soluciones

- Clarificación de soluciones para merill crowe

- $\quad$ Filtrado de partículas/flóculos en plantas ADR

\section{Filtro decantador centrífugo}

- Filtrado de partículas/flóculos hasta $30 \mathrm{u}$ en plantas ADR

\section{Decanter}

- Preparar relave en pasta/filtrado

- $\quad$ Filtrado de concentrados y lodos de plantas de tratamiento de efluentes

\section{Filtro cerámico. Nanofiltración}

- $\quad$ Filtrado de partículas hasta $0.1 \mathrm{u}$

- Uso de cartucho de carburo de silicio

\section{Filtro de membranas}

- Filtrado de partículas/floculos de 5-10u en plantas ADR

- Autolimpiables 


\section{Aplicaciones de equipos centrífugos para minería}

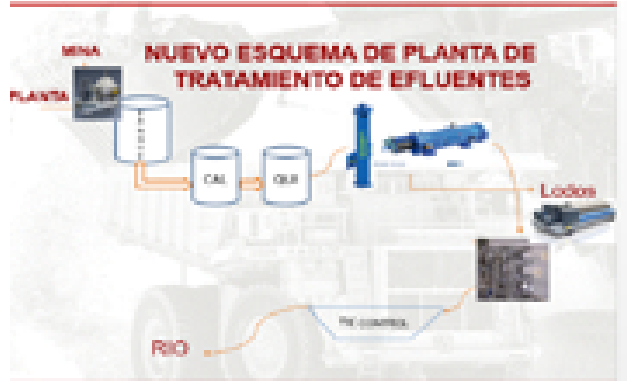

Figura 2. Esquema: planta de tratamiento nueva.

Fuente: elaboración propia

\section{Principales ventajas en la aplicación de equipos centrífugos}

\section{Protegen las boquillas de asper- sión y los orificios pequeños}

"Evitan el ensuciamiento, atascamientos y/o desgaste. Eliminan los períodos de interrupción del servicio y el mantenimiento y/o reemplazo de piezas". (Induserviceecuador.com)

\section{Extienden la vida de los sistemas de filtración fina y de los sistemas de tratamiento de agua}

"Reducen el consumo de cartuchos de micronaje bajo o de filtros de bolsa, con la remoción previa de sólidos más grandes". (Induserviceecuador.com)

\section{Protegen los intercambiadores de calor}

"Controlan la contaminación por sólidos. Remueven la precipitación de gravilla, escamas e incrustaciones. Mantienen la óptima eficiencia del sistema y evitan la excesiva pérdida de energía". (Induserviceecuador.com)

\section{Evitan la acumulación excesiva de sólidos en fosos, sumideros y tanques}

En las piletas de las torres de enfriamiento. En las piletas de templado. En los tanques de lavado de piezas. Eliminan la acumulación de sólidos y los inevitables períodos de interrupción del servicio, las remociones a pala y el mantenimiento rutinario. (Induserviceecuador.com)

\section{Minimizan los deshechos}

Extienden la vida de los líquidos de proceso, removiendo los sólidos que causan problemas. Concentran los sólidos separados para su fácil descarte o recuperación / reutilización. Mejore su status con las organizaciones de control del medio ambiente, aportando una economía significativa relacionada al proceso. (Induserviceecuador.com) 


\section{Beneficios en la nueva aplicación de equipos centrífugos}

La nueva aplicación de equipos centrífugos generaría en la minería actual una reducción en los costos de inversión y un tratamiento de los equipos; así mismo, una mayor eficiencia en los procesos se generarían mejor calidad de vida para las personas aledañas a las aguas que se contaminan por los distintos procesos, ya sean mineros agrícolas o industriales, y obtener todos estos beneficios permitiría estar en armonía con la sociedad, el medio ambiente y las distintas autoridades ambientales.

\section{Conclusiones}

Las alternativas planteadas mejorarán, tanto las aguas residuales mineras como la calidad de vida de la población involucrada. Por otra parte, se concluye que pueden suceder los siguientes escenarios.

Menor costo: las plantas con equipos centrífugos son de menor inversión que las plantas tradicionales.

Mejor calidad: la variedad de equipos centrífugos y la nana filtración brindad una con mejor calidad de agua.
Mayor eficiencia: los equipos trabajan grandes cantidades de agua de manera eficientes con menor consumo de energía.

Mayor armonía: la disminución o eliminación de la contaminación ambiental aumenta la armonía entre la industria y la sociedad.

La innovación y aplicación de nuevos equipos centrífugos en las empresas mineras a nivel industrial les permitirá crecer.

\section{Referencias}

Cadena, L. y Cuervo, J. (2018). Evaluación de la planta portátil potabilizadora de agua lluvia en la empresa Postobón S. A. Fundación Universidad de América.

Chambi, Z. (2018). Tratamiento de aguas residuales de lavanderías por el proceso de coagulación-floculación y adsorción.

Confraternizarhoy.blogspot.com (2012).

Coy, J. y González, D, (2016). Formulación de alternativas técnicas y operativas para el mejoramiento de la planta de potabilización del acueducto de Flandes. Tolima.

Johnson, D. y Hallberg K. (2005). Acid mine drainage remediation options: a review.

Induserviceecuador.com. (s.f.) [Página web]. Lakos. sistemas de separación de líquidos sólidos. Recuperado de

http://www.induservicesecuador.com/descargas/liquidos.pdf 
Ivoflores.blogspot.com (2010). [Blog]. Contaminación en los ríos. Recuperado de http://lvoflores.blogspot.com/2010/07/contaminacion-en-los-rios.html

Rimarachin, P. y Moreno, H. (2015). Tratamiento de aguas de efluentes minero-metalúrgicos utilizando, métodos pasivos y activos en sistemas experimentales.

SUNASS (2015). Diagnóstico de las plantas de tratamiento de aguas residuales en el ámbito de operación de las entidades prestadoras de servicios de saneamiento. Perú. 